\title{
The IOC's endeavour to protect the health of the athlete continues
}

\section{Kathrin Steffen, ${ }^{1,2}$ Torbjørn Soligard, ${ }^{2}$ Lars Engebretsen ${ }^{1,2}$}

After the 2010 Olympic Games in Vancouver, the International Olympic Committee (IOC) has initiated a new project together with the International Olympic Sports Federations (IFs) and the National Olympic Committees (NOC). The aim of the Health, Safety and Security (HSS) survey was to identify and, in turn, eliminate risk factors which could potentially be harmful for the Olympic athletes. Each Federation shared their data on, athletes' risk exposure, technical development and equipment evolution, venue safety procedures, rule change mechanisms and determination of athlete eligibility. The IOC and the IFs are optimistic that this survey will not only increase the awareness on injury prevention, but also facilitate the introduction of tailored measures to prevent injuries and illnesses in each sport and discipline.

With this objective in mind, the IOC have during recent years developed several new programmes. ${ }^{1}$ The injury and illness surveillance system, developed in cooperation with IFs and NOCs, was implemented with success in the 2008 Beijing (injury surveillance only) ${ }^{2}$ and in the 2010 Vancouver Olympics, ${ }^{3}$ and will be further developed in the 2012 London and 2014 Sochii Olympics. Based on a consensus meeting on Periodic Health Exams (PHE), ${ }^{4}$ the IOC is developing an Electronic Medical Record (EMR) system for NOCs, which will not only simplify daily patient consultation in their Olympic Clinics, but also enable longitudinal monitoring of athletes' injuries and diseases both in-between and during the Olympic Games. Such long-term medical follow-up, with implementation of PHEs and subsequent data entry in EMRs, may prove to be instrumental in protecting the health of the athletes in the long-term.

'Department of Sports Medicine, Norwegian School of Sports Sciences, Oslo Sports Trauma Research Center, Oslo, Norway

${ }^{2}$ Medical \& Scientific Department, International Olympic Committee, Lausanne, Switzerland

Correspondence to Kathrin Steffen, Department of Sports Medicine, Norwegian School of Sports Sciences, Oslo Sports Trauma Research Center, P.O. 4014 Ullevi Stadion 0slo, Norway; kathrin.steffen@nih.no
The expert group convened by the $\mathrm{IOC}^{4}$ recommends, 12-lead ECG exams to be an integral part of the PHE. Acknowledging the skill needed to read these ECGs in highlevel athletes, the IOC will in September this year run a pilot course for NOCs' medical personnel on the interpretation of ECGs. If this course is successful, it will be repeated regularly in all continents.

Similarly, the IOC is running two consensus meetings annually in Lausanne, Switzerland. This year's first meeting on Fitness \& Health of Children through Sports will be featured in the September issue of BJSM Injury Prevention and Health Protection (IPHP), whereas last year's two consensus meetings on Age Determination in High-level Young Athletes ${ }^{5}$ and on the use of Platelet Rich Plasma in Sports Medicine ${ }^{6}$ have led to several new studies in these fields, some of them with IOC support.

On the same note, the four IOC research centres on the prevention of injury and protection of the athletes' health are widely publishing on different prevention issues and are leading the way in translating new scientific knowledge into injury and illness prevention practice. Their work will - besides being published in international sports medicine journals be available through the IOC website, so you need to put http://www.olympic.org in your browser favorites!

Many of you have recently attended the World Conference on Prevention of Injury \& Illness in Sport in Monaco. The IOC will follow-up this success with a new World Conference in 2014, highlighting your research and the latest advances in the field in the 3 years that have passed. In the meantime, the IOC is one of the four partners in the International Convention on Science, Education and Medicine in Sport (ICSEMIS) conference taking place in Glasgow 19-23 July 2012, just prior to the London Olympics. Here, sports science and sports medicine will come together and present a wide variety of symposia, lectures and abstracts on issues related to high level athletes and the Olympic Games.

Furthermore, the IOC has in the recent months published three exciting new books (http://www.olympic.org, http:// www.wiley.com): For those of you working with competitive paralympic athletes, The Handbook on the Paralympic Athlete is a must! Furthermore, two new titles supply the IOC series of Encyclopedias of Sports Medicine. The new Genetic and Molecular Aspects of Sports Performance is a wonderful and timely update on where we currently stand in this field. Likewise, the encyclopedia on Neuromuscular Aspects of Sports Performance combines the basics of mechanistic knowledge with guidance on the application of science to understand the influence of training load and to predict and enhance performance.

Finally, we want to highlight the extensive scientific work of UEFA (Union of European Football Associations) and their research team at the Linköping University during the recent years. ${ }^{7}$ Spurred by a concern over the physical and mental demands of the modern professional footballer - and the encompassing injury risk - UEFA has initiated and established injury surveillance among elite football clubs across Europe.

They are not alone! Over the past years, other influential sport organisations such as the IOC, FIFA (Fédération Internationale de Football Association), FIS (Fédération Internationale de Ski), FINA (Fédération Internationale de Natation), IAAF (International Association of Athletics Federations) and FIVB (Fédération Internationale de Volleyball) have put increasing effort into collecting data on the injury risk among elite and amateur athletes. What do these studies add? Do their findings have implications for the athlete? We definitively think so!

The main findings of the UEFA study (see page 553) are that the injury risk in the professional football has plateaued over a 7-year period. ${ }^{7}$ Also, perhaps confirming anecdotal data from the clinics, a hamstring strain is still the single most common injury type at elite level.

The message from this and other longterm projects initiated by the IOC and the IFs is that we need to monitor the development of injury and illness rates over several years to identify hazardous disciplines and sports. By acquiring new knowledge on injury trends, we can optimise and target future research on injury risk factors, mechanisms and finally, prevention.

The key to a meaningful study of epidemiology lies in a well-organised procedure for data collection with coordinated efforts from sports medicine professionals, coaches and athletes, combined with systematic subsequent analyses. Read the UEFA study and learn! 
Competing interests None.

Provenance and peer review Commissioned; not externally peer reviewed.

Br J Sports Med 2011;45:551-552.

doi:10.1136/bjsports-2011-090070

\section{REFERENCES}

1. Rogge J. An ounce of prevention? Br J Sports Med 2009;43:627.
2. Junge A, Engebretsen L, Mountjoy ML, et al. Sports injuries during the Summer Olympic Games 2008. Am J Sports Med 2009;37:2165-72.

3. Engebretsen L, Steffen K, Alonso JM, et al. Sports injuries and illnesses during the Winter Olympic Games 2010. Br J Sports Med 2010;44:772-80.

4. Ljungqvist $\mathbf{A}$, Jenoure $P$, Engebretsen $L$, et al. The International Olympic Committee (IOC) Consensus Statement on periodic health evaluation of elite athletes March 2009. Br J Sports Med 2009:43:631-43.
5. Engebretsen L, Steffen K, Bahr R, et al. The International Olympic Committee Consensus statement on age determination in high-level young athletes. Br J Sports Med 2010:44:476-84.

6. Engebretsen L, Steffen K, Alsousou J, et al. IOC consensus paper on the use of platelet-rich plasma in sports medicine. Br J Sports Med 2010;44:1072-81.

7. Ekstrand J, Hägglund $\mathrm{M}$, Walden $\mathrm{M}$. Injury incidence and injury patterns in professional football: the UEFA injury study. Br J Sports Med 2011:45:553-558.

$\underset{\sim}{\infty}$ 